Case Report

\title{
Another Report of Acalculous Cholecystitis in a Greek Patient with Infectious Mononucleosis: A Matter of Luck or Genetic Predisposition?
}

\author{
Theocharis Koufakis and Ioannis Gabranis \\ Department of Internal Medicine, General Hospital of Larissa, 1 Tsakalof Street, 41221 Larissa, Greece \\ Correspondence should be addressed to Theocharis Koufakis; thkoyfak@hotmail.com
}

Received 24 November 2015; Accepted 21 December 2015

Academic Editor: Atsushi Irisawa

Copyright (c) 2016 T. Koufakis and I. Gabranis. This is an open access article distributed under the Creative Commons Attribution License, which permits unrestricted use, distribution, and reproduction in any medium, provided the original work is properly cited.

\begin{abstract}
We here report a case of a young, male patient who presented with jaundice and was diagnosed with acalculous cholecystitis during the course of a primary Epstein-Barr Virus (EBV) infection. The coexistence of cholestatic hepatitis and acalculous cholecystitis in patients with infectious mononucleosis is extremely uncommon and only few cases can be found in the literature. Moreover, almost one-fourth of the total reports of this rare entity are coming from Greece. Whether this is a result of physicians' high index of suspicion due to previous reports or a consequence of genetic predisposition is an issue that deserves further investigation in the future. More studies are required in order to clarify the pathophysiological and genetic backgrounds that connect acalculous cholecystitis and EBV infection.
\end{abstract}

\section{Introduction}

Infectious mononucleosis (IM), first described by Sprunt and Evans in 1920, is a clinical entity caused by the EpsteinBarr Virus (EBV). EBV, also known as human herpesvirus 4 , is a member of the herpes virus family, composed of a double helix of DNA of approximately 172,000 base pairs and containing about 85 genes [1]. Apart from IM, the virus has been associated with the pathogenesis of various diseases, including Burkitt's lymphoma, Hodgkin's lymphoma, gastric cancer, nasopharyngeal carcinoma, multiple sclerosis, and lymphomatoid granulomatosis [2].

IM is characterized by global geographical distribution, being more frequent among children and young adults [3]. Still, it can be diagnosed in patients of any age, from neonates to the elderly. The virus is transmitted through direct contact with an infected individual. In many cases, the infected subjects remain asymptomatic. When present, the characteristic clinical features include fever, pharyngitis, and lymphadenopathy [4]. Other common manifestations of the disease are fatigue, anorexia, nausea, splenomegaly, arthralgias, and myalgias.
Liver involvement is not unusual during the course of EBV infection, usually being mild and self-limited [5]. However, jaundice is an atypical presentation of the disease, observed only in 5\% of patients with IM [6]. The exact pathophysiological background of jaundice development in IM is still uncertain. Cholestasis and virus-induced hemolysis have been proposed as the most probable mechanisms [5, 7]. Moreover, the coexistence of cholestatic hepatitis and acalculous cholecystitis in patients with IM is extremely uncommon and only few reports can be found in the literature.

\section{Case Presentation}

A 21-year-old male patient presented to the emergency department complaining about icteric skin 24 hours earlier. His past medical history was unremarkable and he was not on any medication. He denied any history of smoking or alcohol intake and there was no significant family history. Patient's physical examination revealed icteric skin and sclera. He did not mention unprovoked abdominal pain. Tenderness of upper right quadrant was noticed only during abdomen palpation (positive Murphy sign). Interestingly, no peripheral 
TABLE 1: Main characteristics of cases with EBV-induced acute acalculous cholecystitis (AAC), reported from Greece.

\begin{tabular}{lccccc}
\hline 1st author, year (ref.) & Age, sex & ALT (IU/L) & Total bilirubin & ALP (IU/L) & Surgical intervention \\
\hline Prassouli, 2007 [7] & 13, female & $674(5-45)$ & $4 \mathrm{mg} / \mathrm{dL}$ & $721(<248)$ & No \\
Lagona, 2007 [8] & 4, female & $304(5-45)$ & $4.6 \mathrm{mg} / \mathrm{dL}$ & $236(38-148)$ & No \\
Attilakos, 2009 [9] & 5, male & $257(5-45)$ & $1.8 \mathrm{mg} / \mathrm{dL}$ & $919(38-148)$ & No \\
Cholongitas, 2009 [10] & 19, female & 584 & $6.5 \mathrm{mg} / \mathrm{dL}$ & 710 & No \\
Fretzayas, 2014 [11] & 11, female & 198 & $31 \mu \mathrm{mol} / \mathrm{L}$ & 536 & No \\
Fretzayas, 2014 [11] & 12, female & 195 & Not provided & Not provided & No \\
Present case & 21, male & $232(<40)$ & $6.31 \mathrm{mg} / \mathrm{dL}$ & $179(<140)$ & No \\
\hline
\end{tabular}

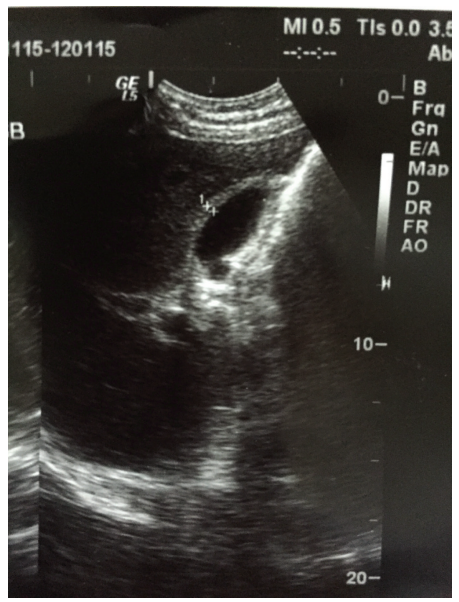

FIGURE 1: Abdominal ultrasound revealing thickening of the gallbladder wall and absence of stones or dilatation of the biliary tract.

lymphadenopathy or exudative pharyngitis was observed. Low-grade fever was noticed during the time of hospitalization.

Laboratory tests on admission were as follows: aspartate aminotransferase $172 \mathrm{IU} / \mathrm{L}$ (normal < $40 \mathrm{IU} / \mathrm{L}$ ), alanine aminotransferase $232 \mathrm{IU} / \mathrm{L}$ (normal $<40 \mathrm{IU} / \mathrm{L}$ ), total bilirubin $6.31 \mathrm{mg} / \mathrm{dL}$ (normal $<1 \mathrm{mg} / \mathrm{dL}$ ), direct bilirubin $4.96 \mathrm{mg} / \mathrm{dL}$ (normal $<0.3 \mathrm{mg} / \mathrm{dL}$ ), alkaline phosphatase $179 \mathrm{IU} / \mathrm{L}$ (normal < $140 \mathrm{IU} / \mathrm{L}$ ), gamma-glutamyl transferase $350 \mathrm{IU} / \mathrm{L}$ (normal < $30 \mathrm{IU} / \mathrm{L})$, lactate dehydrogenase $1141 \mathrm{IU} / \mathrm{L}$ (normal < $350 \mathrm{IU} / \mathrm{L}$ ), prothrombin time 14.2 s (normal 11$14 \mathrm{~s}$ ), international normalized ratio (INR) 1.07, C-Reactive Protein $3.3 \mathrm{mg} / \mathrm{dL}$ (negative $<0.5 \mathrm{mg} / \mathrm{dL}$ ), and white cell count $11 \times 10^{3}$ with $57 \%$ lymphocytes. Abdominal ultrasound revealed mild splenomegaly, thickening of the gallbladder wall $(4.5 \mathrm{~mm})$ (Figure 1), and positive sonographic Murphy sign. No stones, dilatation of the biliary tract, gallbladder swelling, or debris was detected.

The diagnosis of IM was established by high levels of IgM antibodies against EBV viral capsid antigen $(>320 \mathrm{U} / \mathrm{mL}$, nor$\mathrm{mal}<20 \mathrm{U} / \mathrm{mL}$ ). Viral hepatitis markers as well as antibodies for other hepatotropic viruses, human immunodeficiency virus (HIV) test, and blood and urine cultures proved to be negative.

No special treatment was administered apart from intravenous fluids. Our patient had an uneventful recovery and was discharged 10 days after admission, presenting significant improvement of his laboratory tests. Surgical intervention was thought to be unnecessary. In his follow-up visits, he remained in good physical condition and his liver tests gradually normalized within the next 2 months. Abdominal ultrasound repeated 30 days after admission demonstrated normal findings.

\section{Discussion}

Acute acalculous cholecystitis (AAC) is identified as the cause of about 5 to $10 \%$ of all cases of acute cholecystitis [12]. Being more frequent among patients with severe underlying conditions such as trauma and sepsis, it has been linked with higher percentages of mortality and complications when compared to the calculous type of the disease [13]. Though viral AAC is generally uncommon, several case reports of hepatitis A virus-induced AAC have been published in the literature $[14,15]$. Direct invasion of the gallbladder wall by the EBV could be a possible explanation of the development of AAC during the course of IM [16]; still other mechanisms might be also involved. Attilakos et al. [9] discuss a potential contributing role of Gilbert's syndrome to the development of AAC in children with acute EBV infection. Fretzayas et al. [11] consider that biliary dyskinesia could be an alternative explanation of impaired gallbladder contractility in EBV infection.

Interestingly, the vast majority of patients previously reported with coexistence of AAC and EBV infection were females [16], suggesting a probable relationship between estrogens and the development of the disease [17]. Additionally, abdominal pain was prominent in most of the cases and it was the main reason that urged patients to seek medical advice. Differently, peripheral lymphadenopathy was generally absent, in contrast with the typical pattern of IM.

Most cases come from Europe and it is worth pointing out that 6 of them have been already reported from Greece [7-11] (Table 1). Whether this is a result of physicians' high index of suspicion due to previous reports or a consequence of genetic predisposition is an issue that deserves further investigation in the future.

It is worth mentioning that most of formerly described cases received antibiotics, while only one was subjected to cholecystectomy, because of severe clinical condition [18]. However, existing evidence suggests that supportive care and close monitoring of liver function tests are usually adequate 
management strategies for patients with EBV-induced AAC. The possibility of rash development associated with antibiotic treatment in subjects with IM [19] should also be considered.

Gallbladder wall thickening has been also reported in patients with acute hepatitis [20]. However, we consider that the wall thickening of patient's gallbladder in the reported case was a consequence of the developed AAC. Currently, there are no universally accepted criteria for the diagnosis of AAC. Gallbladder wall thickening of over $3 \mathrm{~mm}$, distention of the gallbladder, localized tenderness, and pericholecystic fluid and sludge have been proposed as suitable ones [21, 22]. The combination of two or more of the above criteria, in a compatible clinical setting, is considered to be diagnostic [21]. Our patient met two of the reported criteria, that is, wall thickening $(4.5 \mathrm{~mm})$ and localized tenderness. Generally, a gallbladder wall thickness of at least $3.5 \mathrm{~mm}$ is accepted to be diagnostic of AAC [12].

In contrast with previous reports, our patient was a male and older than the majority of other cases. Moreover, he did not present with abdominal pain, but his main clinical manifestation was jaundice. Consistent with other cases, he did not develop pharyngitis and lymphadenopathy.

In conclusion, the coexistence of cholestatic hepatitis and acalculous cholecystitis represents a rare and atypical presentation of infectious mononucleosis. Physicians should be aware of this uncommon combination and suspect in time a possible EBV infection, in order to avoid unnecessary use of antibiotics or surgical procedures. Further studies are required in order to clarify the pathophysiological and genetic backgrounds that connect acalculous cholecystitis and EBV infection.

\section{Conflict of Interests}

The authors declare that there is no conflict of interests regarding the publication of this paper.

\section{References}

[1] W. Amon and P. J. Farrell, "Reactivation of Epstein-Barr virus from latency," Reviews in Medical Virology, vol. 15, no. 3, pp. 149$156,2005$.

[2] E. Grywalska and J. Rolinski, "Epstein-Barr virus-associated lymphomas," Seminars in Oncology, vol. 42, no. 2, pp. 291-303, 2015.

[3] S. Singer-Leshinsky, "Pathogenesis, diagnostic testing, and management of mononucleosis," Journal of the American Academy of Physician Assistants, vol. 25, no. 5, pp. 58-62, 2012.

[4] T. Bravender, "Epstein-Barr virus, cytomegalovirus, and infectious mononucleosis," Adolescent Medicine: State of the Art Reviews, vol. 21, no. 2, pp. 251-264, 2010.

[5] H. B. Jenson, "Acute complications of Epstein-Barr virus infectious mononucleosis," Current Opinion in Pediatrics, vol. 12, no. 3, pp. 263-268, 2000.

[6] Z. H. Tan, K. B. Phua, C. Ong, and A. Kader, "Prolonged hepatitis and jaundice: a rare complication of paediatric Epstein-Barr virus infection," Singapore Medical Journal, vol. 56, no. 07, pp. el12-e115, 2015.
[7] A. Prassouli, J. Panagiotou, M. Vakaki et al., "Acute acalculous cholecystitis as the initial presentation of primary Epstein-Barr virus infection," Journal of Pediatric Surgery, vol. 42, no. 1, pp. E11-E13, 2007.

[8] E. Lagona, F. Sharifi, A. Voutsioti, A. Mavri, M. Markouri, and A. Attilakos, "Epstein-barr virus infectious mononucleosis associated with acute acalculous cholecystitis," Infection, vol. 35, no. 2, pp. 118-119, 2007.

[9] A. Attilakos, A. Prassouli, G. Hadjigeorgiou et al., "Acute acalculous cholecystitis in children with Epstein-Barr virus infection: a role for Gilbert's syndrome?" International Journal of Infectious Diseases, vol. 13, no. 4, pp. e161-e164, 2009.

[10] E. Cholongitas, K. Katsogridakis, and M. Dasenaki, "Acalculous cholecystitis during the course of acute Epstein-Barr virus infection," International Journal of Infectious Diseases, vol. 13, no. 3, pp. el29-e130, 2009.

[11] A. Fretzayas, M. Moustaki, A. Attilakos, T. Brozou, and P. Nicolaidou, "Acalculous cholecystitis or biliary dyskinesia for Epstein-Barr virus gallbladder involvement?” Prague Medical Report, vol. 115, no. 1-2, pp. 67-72, 2014.

[12] C. Iaria, L. Arena, G. Di Maio et al., "Acute acalculous cholecystitis during the course of primary Epstein-Barr virus infection: a new case and a review of the literature," International Journal of Infectious Diseases, vol. 12, no. 4, pp. 391-395, 2008.

[13] F.-L. Liu, H. Li, X.-F. Wang et al., "Acute acalculous cholecystitis immediately after gastric operation: case report and literatures review," World Journal of Gastroenterology, vol. 20, no. 30, pp. 10642-10650, 2014.

[14] S. Kaya, A. E. Eskazan, N. Ay et al., "Acute acalculous cholecystitis due to viral hepatitis A," Case Reports in Infectious Diseases, vol. 2013, Article ID 407182, 4 pages, 2013.

[15] Ö. Herek, N. Çördük, D. Herek, and Ș. Bagci, "Acute acalculous cholecystitis due to hepatitis A infection in a child: a rare cause of acute abdomen," Annals of African Medicine, vol. 10, no. 2, pp. 193-195, 2011.

[16] J. Agergaard and C. Larsen, "Acute acalculous cholecystitis in a patient with primary Epstein-Barr virus infection: a case report and literature review," International Journal of Infectious Diseases, vol. 35, pp. 67-72, 2015.

[17] S. I. Myers, "The role of eicosanoids in experimental and clinical gallbladder disease," Prostaglandins, Leukotrienes and Essential Fatty Acids, vol. 45, no. 3, pp. 167-180, 1992.

[18] S. Hagel, T. Bruns, M. Kantowski, P. Fix, T. Seidel, and A. Stallmach, "Cholestatic hepatitis, acute acalculous cholecystitis, and hemolytic anemia: primary Epstein-Barr virus infection under azathioprine," Inflammatory Bowel Diseases, vol. 15, no. 11, pp. 1613-1616, 2009.

[19] A. C. LeClaire, C. A. Martin, and A. D. Hoven, "Rash associated with piperacillin/tazobactam administration in infectious mononucleosis," Annals of Pharmacotherapy, vol. 38, no. 6, pp. 996-998, 2004.

[20] K. T. Suk, C. H. Kim, S. K. Baik et al., "Gallbladder wall thickening in patients with acute hepatitis," Journal of Clinical Ultrasound, vol. 37, no. 3, pp. 144-148, 2009.

[21] F. Alkhoury, D. Diaz, and J. Hidalgo, "Acute acalculous cholecystitis (AAC) in the pediatric population associated with Epstein-Barr Virus (EBV) infection. Case report and review of the literature," International Journal of Surgery Case Reports, vol. 11, pp. 50-52, 2015.

[22] E. A. Deitch and J. M. Engel, "Acute acalculous cholecystitis. Ultrasonic diagnosis," The American Journal of Surgery, vol. 142, no. 2, pp. 290-292, 1981. 


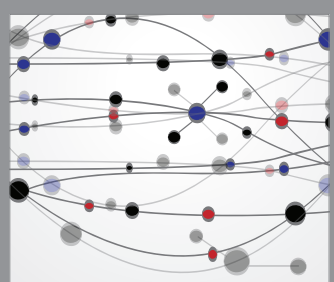

The Scientific World Journal


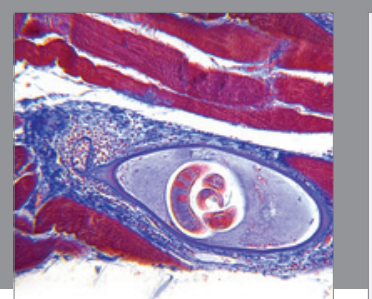

Gastroenterology Research and Practice

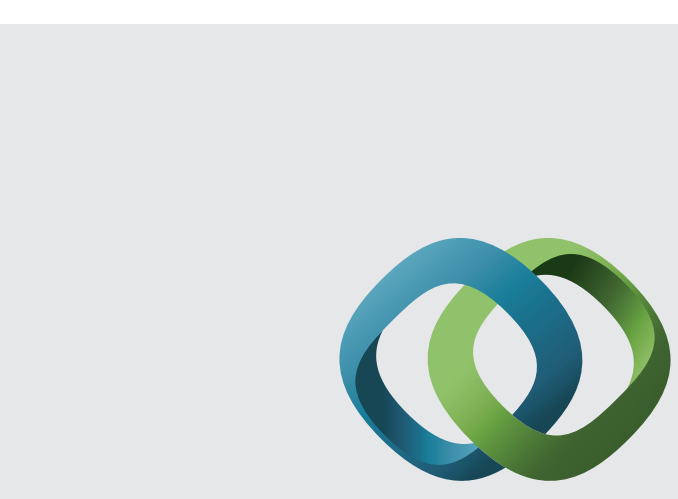

\section{Hindawi}

Submit your manuscripts at

http://www.hindawi.com
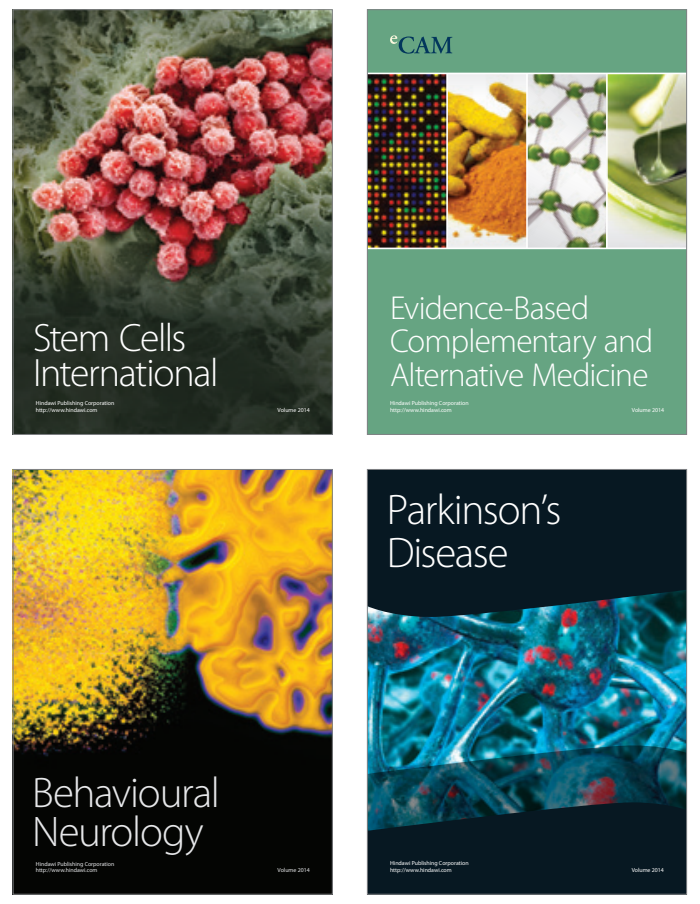
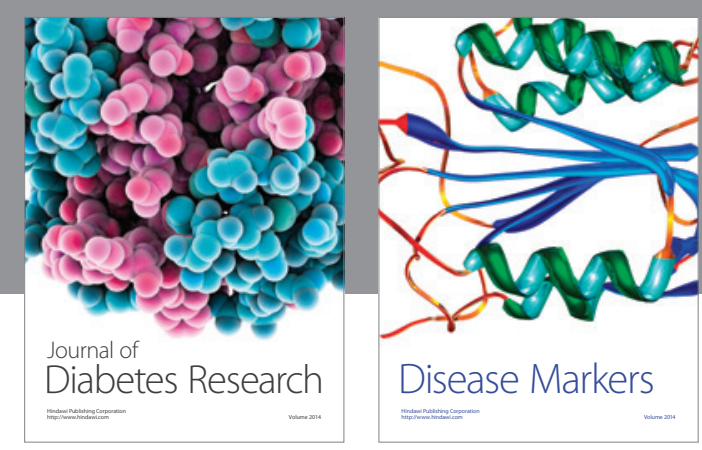

Disease Markers
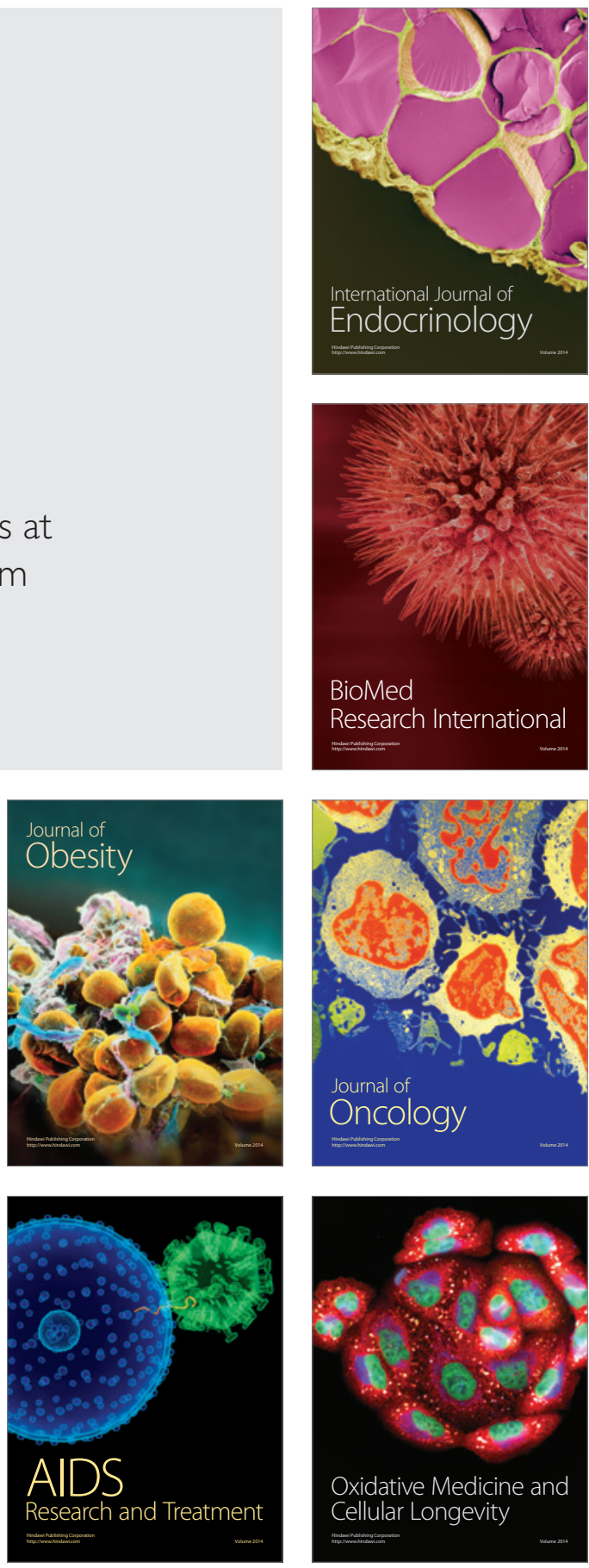